\title{
PENYULUHAN DAN PELATIHAN KADER POSYANDU SEBAGAI UPAYA PENINGKATAN WAWASAN PELAYANAN GIZI BAGI MASYARAKAT
}

\author{
Rahmawati ${ }^{* *}$, Niken Widyastuti Hariati ${ }^{2}$, Icha Dian Nurcahyani ${ }^{3}$, Fitri Wahyuni ${ }^{4}$ \\ 1,3,4 Prodi S1 Gizi, STIKes Salewangang Maros, Indonesia \\ ${ }^{2}$ Prodi DIII Gizi, Poltekkes Kemenkes Banjarmasin, Indonesia \\ ${ }^{1}$ rahmazahrah@yahoo.com, ${ }^{2}$ niken.widyastuti.hariati@gmail.com, \\ ${ }^{3}$ icha.nurcahyani@gmail.com, ${ }^{4}$ fitriwahyuni.am@gmail.com
}

\begin{abstract}
ABSTRAK
Abstrak: Peran aktif kader kesehatan dipelayanan gizi sangat penting untuk meningkatkan kualitas dan status gizi masyarakat terutama kesehatan ibu dan anak. Aktif tidaknya kader tersebut tergantung dari pengetahuan kader Posyandu. Kegiatan ini bertujuan untuk melakukan penyuluhan dan pelatihan kader posyandu agar lebih meningkatkan wawasan tentang pelayanan gizi di posyandu. Kegiatan pengabdian dilakukan melalui beberapa tahap yaitu tahap persiapan (observasi), tahap pelaksanaan, dan tahap evaluasi. Tahap awal dilakukan pengumpulan data melalui wawancara dan kuesioner (pre-test). Tahap inti dilakukan penyuluhan tentang 5 meja posyandu, MP ASI, PMT penyuluhan dan pemulihan, GTM, kemudian pelatihan pengisian KMS dan cara membaca grafik KMS, serta cara melakukan pengukuran status gizi yang baik dan benar. Tahap akhir dilakukan evaluasi melalui tanya jawab dan post-test untuk mengetahui tingkat pemahaman kader posyandu setelah penyuluhan. Hasil pre-test rata-rata pengetahuan kader sebesar $57.8 \%$ dan post-test sebesar $73.3 \%$. Hasil tersebut dapat disimpulkan bahwa pengetahuan kader meningkat setelah diberikan penyuluhan dan pelatihan.
\end{abstract}

Kata Kunci: Pelayanan Masyarakat, Kader Posyandu, Status Gizi

\begin{abstract}
The active role of health cadre in nutritional care is very important to improve the quality and nutritional status of the community especially maternal and child health. Active or not active the cadre is dependent on the knowledge of Posyandu cadres. This activity aimed to provide counseling and training Posyandu cadres to improve the knowledge of nutritional care in the Posyandu. The dedication activities were conducted through several stages namely the preparation stage (observation), the implementation stage, and the evaluation stage. The first stage was data collection through interviews and questionnaires (pre test). The core stage was carried out counseling about of five Posyandu table, MP ASI, PMT extension and recovery, GTM, then the training of filling $K M S$ and how to read KMS charts, as well as how to perform the measurement of good and correct nutritional status. The final stage was evaluated through the question and answer post-test to know the level of understanding Posyandu cadres after counseling. The results of pre test average cadre knowledge of $57.8 \%$ and post test of $73.3 \%$. The results could be concluded that cadre knowledge increased after being given counseling and training.
\end{abstract}

Keywords: Community Service, Posyandu Cadres, Nutritional Status

\section{A. LATAR BELAKANG}

Posyandu merupakan salah satu bentuk Upaya Kesehatan Bersumberdaya Masyarakat (UKBM) yang dikelola dari, oleh, untuk, dan bersama masyarakat, guna memberdayakan masyarakat dan memberikan kemudahan kepada masyarakat dalam memperoleh pelayanan kesehatan dasar. Upaya peningkatan peran dan fungsi Posyandu bukan semata-mata 
tanggung jawab pemerintah saja, namun semua komponen yang ada di masyarakat, termasuk kader. Peran kader dalam penyelenggaraan Posyandu sangat besar karena selain sebagai pemberi informasi kesehatan kepada masyarakat juga sebagai penggerak masyarakat untuk datang ke Posyandu dan melaksanakan perilaku hidup bersih dan sehat (Husniyawati \& Wulandari, 2016).

Pelayanan gizi adalah salah satu kegiatan posyandu yang selalu dilakukan setiap bulan sekali. Pelayanan gizi di Posyandu dilakukan oleh kader yang bentuk pelayanannya meliputi penimbangan berat badan, pengisian KMS, deteksi dini gangguan pertumbuhan, penyuluhan gizi, pemberian PMT, pemberian vitamin A dan pemberian sirup besi $(\mathrm{Fe})$. Untuk ibu hamil dan ibu nifas diberikan tablet besi dan yodium untuk daerah endemis gondok (Hara, Adhi, \& Pangkahila, 2014), (Mulat, 2017).

Kader adalah tenaga suka rela yang dipilih oleh dan dari masyarakat yang bertugas dimasyarakat. Kegiatan gizi di posyandu merupakan salah satu kegiatan utama dan umumnya menjadi prioritas dalam pelaksanaan kegiatan Posyandu. Peran aktif kader kesehatan dipelayanan gizi sangat penting untuk meningkatkan kualitas dan status gizi masyarakat terutama kesehatan ibu dan anak. Aktif tidaknya kader tersebut tergantung dari pengetahuan kader Posyandu Kader posyandu merupakan health provider yang berada di dekat kegiatan sasaran posyandu, tatap muka kader lebih sering daripada petugas kesehatan lainnya (Miza, 2015), (Rahayu, 2017).

Hasil wawancara yang dilakukan ke koordinator kader Posyandu di Kelurahan Pallantikang, ternyata hampir sebagian besar kader belum mengetahui fungsi utama dalam kegiatan Posyandu seperti pengisian KMS yang baik dan benar, fungsi dari 5 meja di Posyandu, dan penyuluhan gizi dan PMT yang harusnya dilakukan oleh kader posyandu.

Berdasarkan hal tersebut, kami merasa perlu untuk mengadakan sebuah kegiatan pelatihan dan penyuluhan untuk para kader posyandu agar lebih meningkatkan wawasan tentang pelayanan gizi di posyandu.

\section{B. METODE PELAKSANAAN}

Pengabdian kepada masyarakat ini dilakukan di Kelurahan Pallantikang, Kecamatan Maros Baru, Kabupaten Maros, pada tanggal 29 Juli 2017 pukul 08.00- selesai WITA. Adapun subjek pengabdian ini yaitu kader Posyandu sebanyak 19 orang.

Kegiatan pengabdian kepada masyarakat dilakukan melalui beberapa tahap yaitu tahap persiapan (observasi), tahap pelaksanaan, dan tahap evaluasi. Tahap awal dilakukan pengumpulan data melalui wawancara dan kuesioner (pre-test). Tahap inti dilakukan penyuluhan tentang 5 meja posyandu, MP ASI (Makanan Pedamping ASI), PMT (Pemenuhan Makanan Tambahan) penyuluhan dan pemulihan, GTM (Gerakan Tutup Mulut) pada anak, kemudian pelatihan pengisian KMS (Kartu Menuju Sehat) dan cara 
membaca grafik KMS, serta cara melakukan pengukuran status gizi yang baik dan benar. Tahap akhir dilakukan evaluasi melalui tanya jawab dan post-test untuk mengetahui tingkat pemahaman kader posyandu setelah penyuluhan dan pelatihan.

\section{HASIL DAN PEMBAHASAN}

Kegiatan Pengabdian kepada masyarakat telah dilaksanakan dengan berbagai bentuk kegiatan berupa penyuluhan pelayanan 5 meja dan pelatihan pengisian KMS. Adapun kegiatan yang dilakukan dapat dilihat pada Gambar 1 berikut.

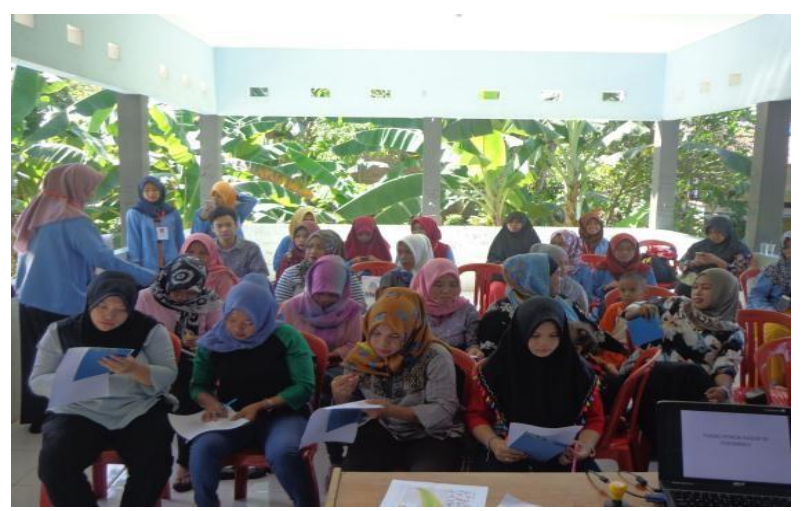

Gambar 1. Kegiatan Penyuluhan Kader Posyandu

Kegiatan ini diikuti oleh 19 kader Posyandu yang berada di Kelurahan Pallantikang Kecematan Maros Baru Kabupaten Maros. Kelurahan ini memiliki 4 Wilayah Posyandu, yaitu Posyandu Marusu, Panaikang, Data, dan Pangkajene. Masing-masing perwakilan kader diberikan edukasi tentang tugas dan fungsi pokok kader di Posyandu.

Sebelum kegiatan inti, peserta diberikan soal multiple choise sejumlah 10 soal sebagai pre-test yang mewakili setiap materi penyuluhan dan pelatihan yang dilakukan. Hasil pre-test yang diperoleh yaitu 57.8\%. Hasil ini membuktikan bahwa pengetahuan kader tentang tugas pokok di Posyandu masih kurang.

Berdasarkan survey awal yang dilakukan melalui sesi wawancara ke koordinator Posyandu, rata-rata kader tergolong baru, beberapa kali telah dilakukan pergantian kader karena alasan sibuk sebagai ibu rumah tangga, pedagang, dan faktor lainnya yang menghambat kegiatan di Posyandu sehingga meskipun transfer pengetahuan pada kader Posyandu di Kelurahan Pallantikang selalu dilakukan melalui penyuluhan di Puskesmas atau Kelurahan oleh petugas kesehatan, tetap akan didapatkan pengetahuan kader yang masih kurang.

Oleh karena itu, kader Posyandu perlu diberikan pengetahuan bukan dari segi skill saja tetapi peran pentingnya yang sangat mulia untuk peningkatan kesehatan masyarakat terutama balita. Kader memegang peranan penting, selain sebagai pelaksana kegiatan posyandu (administrator) dan memberikan penyuluhan (edukator), kader juga 
menggerakkan keaktifan ibu yang mempunyai balita untuk datang ke posyandu (motivator) (Wahyutomo, 2010).

Menurut Wahyutomo (2010) ada hubungan yang signifikan antara lama menjadi kader dan pengetahuan gizi kader dengan pemantauan peningkatan berat badan Balita (Wahyutomo, 2010). Selain itu, semakin lama seseorang bekerja semakin banyak kasus yang ditangani sehingga semakin meningkat pengalamannya. Pengalaman bekerja banyak memberikan keahlian dan keterampilan (Wardhani, 2012), (Isra, Chriswardani Suryawati, \& Kartini, 2014).

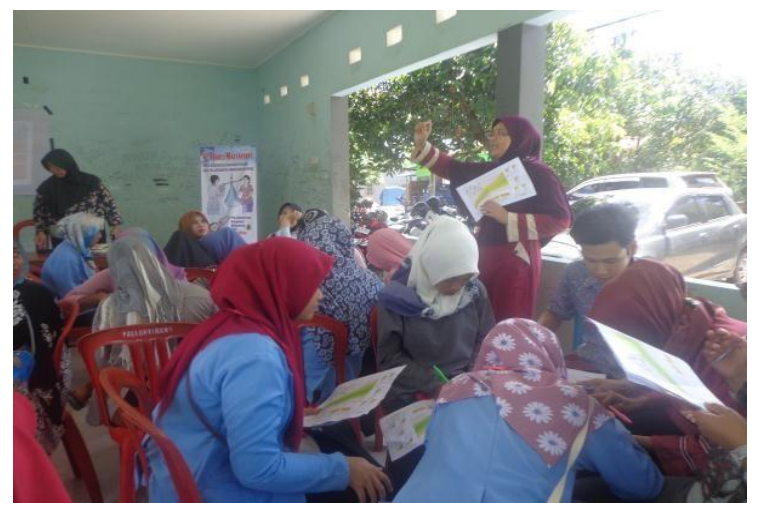

Gambar 2. Kegiatan Pelatihan Pengisian KMS

Adanya kegiatan pengabdian kepada masyarakat ini sangat memberikan dampak positif pada kader Posyandu. Kader Posyandu yang awalnya tidak mengetahui secara detail tugas pokok kader menjadi semakin mengetahui peran pentingnya untuk peningkatan kesehatan ibu dan anak di Posyandu. Adanya peran kader dapat membantu masyarakat dalam mengurangi angka gizi buruk, selain itu peran kader juga membantu dalam mengurangi angka kematian ibu juga balita, dengan memanfaatkan keahlian serta fasilitas penunjang lainnya yang berhubungan dengan peningkatan status gizi balita (Helmi Rosmalia, 2013). Hal ini dibuktikan dengan perolehan post-test yang menunjukkan peningkatan menjadi $73.3 \%$. Hara (2014) menyatakan bahwa pengetahuan yang dimiliki oleh seseorang akan membentuk sikap dan menimbulkan suatu perilaku dalam kehidupan sehari-hari (Hara et al., 2014).

\section{SIMPULAN DAN SARAN}

Hasil pengabdian kepada masyarakat ini memperlihatkan bahwa pengetahuan kader Posyandu mengalami peningkatan setelah diberikan intervensi dalam bentuk penyuluhan dan pelatihan. Hasil post-test menunjukan bahwa terdapat peningkatan pengetahuan kader Posyandu setelah dilakukan intervensi penyuluhan dan pelatihan sebesar $73.3 \%$ yang awal pre test hanya $57.8 \%$. Dari hasil tersebut dapat disimpulkan bahwa pengetahuan kader meningkat setelah diberikan penyuluhan dan pelatihan. Kader Posyandu perlu diberikan pengetahuan bukan dari segi skill saja tetapi peran pentingnya yang sangat mulia untuk peningkatan kesehatan 
masyarakat terutama balita sehingga pelaksanaan posyandu dapat berjalan efektif sesuai dengan tujuan dari diadakanya kegiatan posyandu.

\section{DAFTAR RUJUKAN}

Hara, M. K., Adhi, K. T., \& Pangkahila, A. (2014). Pengetahuan Kader dan Perilaku Asupan Nutrisi Berhubungan dengan Perubahan Status Gizi Balita, Puskesmas Kawangu, Sumba Timur. Public Health and Preventive Medicine Archive, 2(1), 33. https://doi.org/10.15562/phpma.v2i1.120

Helmi Rosmalia. (2013). Faktor-Faktor Yang Berhubungan Dengan Status Gizi Pada Balita Di Wilayah Kerja Puskesmas Margototo. Jurnal Kesehatan, IV(1), 233-242. https://doi.org/Volume IV, Nomor 1. April 2013. hlm 233-242 Presentase

Husniyawati, Y. R., \& Wulandari, R. D. (2016). Analisis Motivasi Terhadap Kinerja Kader Posyandu Berdasarkan Teori Victor Vroom. Jurnal Administrasi Kesehatan Indonesia, 4(2), 126. https://doi.org/10.20473/jaki.v4i2.2016.126-135

Isra, W. O. A., Chriswardani Suryawati, \& Kartini, A. (2014). Evaluasi Pelaksanaan Revitalisasi Posyandu dalam Penurunan Prevalensi Balita Gizi Buruk di Kota Baubau Provinsi Sulawesi Tenggara. Jurnal Manajemen Kesehatan Indonesia, 02(03), 232-241.

Miza, T. I. (2015). S2. Strategi Pengembangan Kelembagaan Program Perbaikan Gizi Masyarakat Di Kabupaten Bogor.

Mulat, T. C. (2017). Peran Kader Posyandu Terhadap Upaya Peningkatan Status Gizi Balita (3-5) Tahun Di Wilayah Kerja Puskesmas Batua Kota Makassar. Jurnal Ilmiah Kesehatan Sandi Husada, 5(1), 9-24. https://doi.org/10.35816/jiskh.v5i1.69

Rahayu, S. P. (2017). Hubungan Tingkat Pengetahuan Kader Tentang Pengukuran Antropometri Dengan Ketrampilan Dalam Melakukan Pengukuran Pertumbuhan Balita Di Posyandu Kelurahan Karangasem Kecamatan Laweyan. Program Studi S1 Keperawatan Fakultas Ilmu Kesehatan Universitas Muhammadiyah Surakarta.

Wahyutomo, A. H. (2010). Hubungan Karakteristik Dan Peran Kader Posyandu Dengan Pemantauan Tumbuh Kembang Balita Di Puskesmas Kalitidu-Bojonegoro. Universitas Sebelas Maret, Surakarta.

Wardhani, A. K. (2012). Hubungan Pengetahuan Gizi dan Lama Menjadi kader Posyandu dengan Tingkat Partisipasi Masyarakat di Kelurahan Semanggi Kecamatan Pasar Kliwon Kota Surakarta. Muhammadiyah University of Surakarta. 